\section{Haematological overkill}

The Year in Hematology, 1978. Edited by $\mathbf{R}$. Silber, J. LoBue and A. S. Gordon. Pp. 517. (Plenum Medical: New York and London, 1978.)

ALL the signs are that we are entering a state of literary polycythaemia. For non-clinical readers this means that current scientific writing is suffering from a pathological excess of blood. As well as the increasing number of textbooks and monographs on the subject and a rapidly proliferating series of haematology journals, many of which carry review articles, there are regular review series such as Clinics in ..., Recent Advances in..., Topics in..., Seminars in..., Progress in ..., and many more, all offering minor variations on the same theme. Added to all this the general scientific and medical journals are giving a considerable amount of space to articles on haematological topics, and nearly every international meeting on the subject now insists that authors prepare manuscripts for a published account of the proceedings. Presumably somebody reads all these reviews and the publishing houses and the Inland (and Internal) Revenues (if not the authors) are waxing rich. However, as blood letting rather than transfusion is the more logical approach to the treatment of polycythaemia, surely the appearance of yet another review series in this field must raise serious questions about the value of all this repetitive writing.

The Year in Hematology first appeared in 1977 and on the jacket of the 1978 edition the series is described as offering "a comprehensive overview of the latest findings and trends that have occurred during the last year, critically appraising the most recent observations of normal and abnormal function in the hemopoietic system". A glance at the list of references at the end of each chapter and of their contents indicates that it does no such thing. In fact, this is yet another collection of review articles.

Because of this plethora of activity the editors of new haematological review series must exercise considerable ingenuity in finding topics which have not been covered many times in the previous year or two. In fact, there are one or two subjects which appear in this edition of The Year in Hematology which fall into this category, although not many. For example, the interesting chapters on the regulation of the egress of bone marrow cells, thymosin, and the effects of anti-cancer agents on haemopoietic progenitors deal with areas which have not been over- exposed recently. On the other hand haemoglobin switching, cytogenetic studies in leukaemia, leukaemia antigens, and recent advances in the treatment of Hodgkin's disease and nonHodgkin's lymphoma have all figured with monotonous regularity.

With a few exceptions the subjects covered in the 1978 Year in Hema tology are dealt with thoroughly, referenced adequately and presented clearly. The book is well produced and illustrated. Perhaps it is unfair to judge this series after only two editions but the editors are certainly going to have

\section{Green crop fractionation}

Leaf Protein and Other Aspects of Fodder Fractionation. By N. W. Pirie. Pp. 183. (Cambridge University Press: Cambridge and London, 1978.) $£ 8$.

IMPROVED systems of crop production and utilisation attract world-wide attention. The technique of fractionation to produce high quality foods for humans and simultaneously feeds for farm livestock from fibrous green crops comes into this category. For approaching half a century N. W. Pirie has inspired, with his determination and enthusiasm, much research in both the developing and more developed regions of the world. Students, teachers, scientists and others with a devotion to improving food production, including those with particular interests in fractionation, would do well to read the book and to absorb the vast amount of investigation which has already taken place.

Leaf protein is potentially a most abundant source of protein with a good nutritive value, and temperate and tropical flora examined as sources of extractable protein are numerous. The separation and preparation of good fractionation products is well documented and these can be stored safely to prevent deterioration. A vast amount of qualitative information is already available from the scientific literature and the need now is for more quantitative data: crop and machines used must be thoroughly defined so that the end-products cease to be mysterious. The main challenge now is to assess when the exciting technical potential can be harnessed to provide worthwhile practical systems.

N. W. Pirie has always been interested in the less developed areas of the world and already there is evidence of sub-tropical villagers using leaf protein as food. The expansion of this type of work needs a missionary approach and substantial financial support to act as to use all their imagination to really justify the existence of yet another review series in a field in which the number of 'overviews' seems to be in danger of exceeding the number of original articles which are available to be reviewed. Indeed, the horrid neologism 'overview' seems to be in real danger of taking on a rather different meaning to that which its inventors had in mind!

D. J. Weatherall

D. J. Weatherall is Nuffield Professor of Clinical Medicine at the University of Oxford, UK.

the catalyst. Adoption of the technique has been slow. At the present time a greater interest seems to exist for exploiting the fractionation technique on a factory scale to produce leaf protein more as a source of pigment for poultry rations than as a source of protein. Some units already exist in Europe and North America and a modest expansion of this use of the technique is likely to occur around the world. Whether as a 'village' or a 'factory' operation the prospects for fractionation need discussion and debate. Further research is also required and a number of proposals are made in the chapters of this book.

Greater attention should be directed to improving the efficiency of green crop production and utilisation. Although it is technically possible by fractionation to produce leaf protein, We must not lose sight of the fact that some $80 \%$ of the harvested dry matter is best suited for ruminant consumption and certainly cannot be discarded. In many ways the use of fibrous green crops for human foods is exciting but there is a necessary balance between this and ruminant feeding.

Two centuries after the death of Hilaire Marin Rouelle, who published the first scientific papers on leaf protein, the world is certainly no less dependent on the politicians and the economic climates they create and foster. Progress has been made in green crop fractionation and the prospects are tantalising ecpecially if scientists in the wake of N. W. Pirie can help the necessary biochemical engineering to take place and develop reliable systems robust enough to be profitable compared with alternatives irrespective of the scale and objectives of the operation. Investigation of the future prospects of green crop fractionation deserves support and the book is a timely publication.

J. Commell

J. Connell is Principal Scientific Officer at the National Institute for Research in Dairying, Shinfield, UK. 